\title{
Ordered Search in Differentiated Markets
}

Jidong Zhou

\section{EERI Research Paper Series No 28/2009}

ISSN: 2031-4892

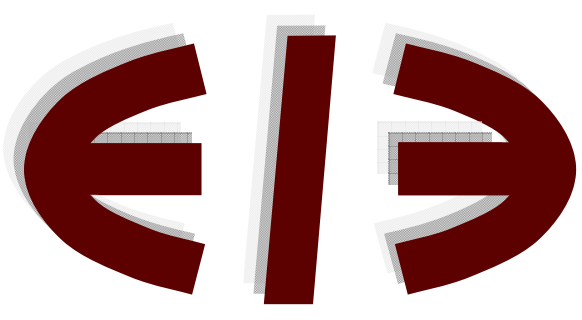

EERI

Economics and Econometrics Research Institute Avenue de Beaulieu 1160 Brussels

Belgium

Tel: +3222993523

Fax: +322 2993523

www.eeri.eu 


\title{
Ordered Search in Differentiated Markets*
}

\author{
Jidong Zhou \\ Department of Economics, University College London \\ This Version: August 2009
}

\begin{abstract}
This note presents an ordered search model in which consumers search both for price and product fitness. We construct an equilibrium in which there is price dispersion and prices rise in the order of search. The top firms in consumer search process, though charge lower prices, earn higher profits due to their larger market shares.
\end{abstract}

Keywords: search, price dispersion, product differentiation

JEL classification: D43, D83, L13

\section{Introduction}

In a variety of circumstances, consumers need to search to find a satisfactory product. However, not as most of the search literature assumes, the order in which consumers search through alternatives is often not random. For example, when facing options presented in a list such as links on a search engine webpage and dishes on a menu, people often consider them from the top down; when shopping in a high street, a bazaar, or a supermarket, consumers' search order is restricted by the spatial locations of sellers or products; when we go to a travel agent to buy airline tickets or a financial advisor to buy a savings product, the advisor may tell us the options one by one in a predetermined order.

This note intends to investigate how non-random consumer search can affect firms' pricing behavior. We study an ordered search model with horizontally differentiated

*I am grateful to Mark Armstrong and John Vickers for helpful discussions. Financial support from the Economic and Social Research Council (UK) and the British Academy is gratefully acknowledged. Contact information: jidong.zhou@ucl.ac.uk. 
products where consumers search both for price and product fitness in an exogenously given order. We show that, when there are no systematic quality differences between products and the search cost is homogenous among consumers, there is an equilibrium in which prices rise with the rank of products. This is essentially because if a consumer visits firms positioned down in her search order, she must have relatively low valuations for early products, which provides later firms extra monopoly power. In such an equilibrium with a rising price sequence, it is indeed rational for consumers to follow the order in which products are presented. ${ }^{1}$ Therefore, even if consumers can control their search orders freely, ordered search can emerge as an equilibrium outcome.

We also show that the top firms in consumer search process, though charge lower prices, earn higher profits due to their larger market shares. This supports the fact that firms are willing to pay for top positions. For instance, manufacturers pay supermarkets for access to prominent positions; firms bid for sponsored links on search engines; and sellers pay more for salient advert slots in yellow page directories.

Arbatskaya (2007) has studied an ordered search model where firms supply a homogeneous product. Since consumers only care about price, in equilibrium the price should decline with the rank of products, otherwise no rational consumer would have an incentive to sample products in unfavorable positions. ${ }^{2}$ In our model with differentiated products, consumers may search on in pursuit of better matched products even if they expect rising prices. Then their search history reveals their preferences, which can significantly change firms' pricing incentive.

The search model with differentiated products is initiated by Wolinsky (1986) and further developed by Anderson and Renault (1999). Both papers consider random consumer search. More recently, Armstrong, Vickers, and Zhou (2009) (AVZ thereafter) use that framework to model prominence, in which all consumers sample a prominent product first and, if it is not satisfactory, they will continue to search randomly among other products. ${ }^{3}$

\footnotetext{
${ }^{1}$ There are other possible reasons why consumers are willing to follow the presentation order. For example, the products in top positions may have higher qualities. See more discussion in the conclusion part.

${ }^{2}$ An earlier paper on ordered consumer search is Perry and Wigderson (1986). There is two-sided asymmetric information in their model: the product is homogenous but each seller has an uncertain cost, and consumers differ in their willingness-to-pay for the product. They also assume no scope for going back to a previous offer. They argue that in equilibrium the observed prices, on average, could be non-monotonic in the order of sellers.

${ }^{3}$ Hortaçsu and Syverson (2004) construct a related empirical non-random search model, where investors sample differentiated mutual funds with unequal probabilities. But they did not explore theoretical predictions of their model, and there is also no empirical conclusion about the relationship between
} 
One main result in AVZ is that the prominent product will be cheaper than others. This note generalizes AVZ by considering a completely ordered search model and obtains a similar result. However, the analysis in AVZ cannot be straightforwardly applied whenever there are more than two firms. The consumer stopping rule in AVZ is stationary since all non-prominent firms charge the same price, while in this note given that different firms charge different prices, the consumer stopping rule becomes non-stationary. This causes extra complication in the analysis and calls for new techniques in proving existence of equilibrium and the profit result. In addition, the stopping rule in the ordered search model crucially depends on the rank of prices. For example, the stopping rule associated with a rising price sequence is qualitatively different from that associated with a declining price sequence. Hence, we need to deal with the issue of multiple equilibria, which is absent is AVZ. We rule out the possibility of equilibrium with a declining price sequence. In the three-firm case, we can also rule out equilibria with non-monotonic price sequences.

The remainder of this note is organized as follows. Section 2 presents the model, and it is analyzed in section 3. Section 4 concludes and discusses possible extensions. Technical proofs are included in the Appendix.

\section{A Model of Ordered Search}

Our underlying model of consumer choice is based on the framework developed by Wolinsky (1986). There are $n \geq 2$ firms indexed by $1,2, \cdots, n$, each supplying a single product at a constant unit cost which we normalize to zero. There are a large number of consumers with measure of one, and each consumer has a unit demand for one product. Consumers have idiosyncratic valuations of products. Specifically, $\left(u_{1}, u_{2}, \cdots, u_{n}\right)$ are the values attached by a consumer to different products, where $u_{k}$ is assumed to be independently drawn from a common distribution $F(u)$ on $\left[u_{\min }, u_{\max }\right]$ which has a positive and differentiable density function $f(u)$; and all match values are also realized independently across consumers. The common-distribution assumption means that there are no systematic quality differences among products. The surplus from buying one unit of firm $k$ 's product at price $p_{k}$ is $u_{k}-p_{k}$. If all match utilities and prices are known, a consumer will choose the product providing the highest positive surplus. If $u_{k}-p_{k}<0$ for all $k$, she will leave the market without buying anything.

We assume that consumers initially have imperfect information about the product prices and the match utilities (but they hold the rational expectation). They can gather

sampling probability and price. 
information through a sequential search process. By incurring a search cost $s>0$, a consumer can find out a product's price and match utility. We assume that the search process is without replacement and there is costless recall (i.e., a consumer can return to any previously sampled product without paying an extra cost). Departing from the traditional search literature, we suppose that all consumers sample firms in an exogenously specified order. Without loss of generality, firm $k$ will be sampled before firm $k+1$.

Firms know their own positions in consumers' search process. They simultaneously set prices $p_{k}(k=1,2, \cdots, n)$ to maximize profit based on their expectations of consumer behavior.

\section{Analysis}

\subsection{Demand}

We first analyze consumers' search behavior. Let $a$ solve

$$
\int_{a}^{u_{\max }}(u-a) d F(u)=s .
$$

If there are no price differences among products and if a consumer has found a product with match value $a$, the benefit from sampling one more product (the left-hand side) is equal to the search cost. As long as the search cost is not too high, $a$ exists uniquely and decreases with $s$. Throughout this paper, we assume the search cost is relatively small such that in equilibrium $p_{k}<a$ for all $k$ and so each firm has a chance to be sampled by consumers. $^{4,5}$

The form of consumers' optimal stopping rule depends on the property of the price sequence in their expectation. Since we aim to construct an equilibrium with $p_{1}<p_{2}<$ $\cdots<p_{n}<a$, we first assume that consumers hold an expectation of an increasing price sequence. We will discuss the issue of multiple equilibria in Section $3.3 .^{6}$

\footnotetext{
${ }^{4}$ When a consumer expects $p_{1}<a$, her expected surplus from sampling product 1 is $\int_{p_{1}}^{u_{\max }}(u-$ $\left.p_{1}\right) d F(u)-s>0$ and so she is willing to participate in the market. Similarly, when a consumer expects $p_{k+1}<a$, there is a positive probability that she will further sample product $k+1$ after sampling the first $k$ products. Therefore, $p_{k}<a$ for all $k$ ensures that every firm is active in the market.

${ }^{5}$ As usual in search models, there are always uninteresting equilibria where consumers only sample the first $k \leq n-1$ products, because they expect that other firms are charging very high prices such that visiting them is not worthwhile at all. Since they do not expect consumers to visit them, those firms have no incentive to lower their prices. We do not consider these equilibria further.

${ }^{6}$ There is no such an issue when $n=2$ or when consumers sample randomly among all other firms after visiting firm 1 as in AVZ.
} 
The Optimal Stopping Rule. Suppose consumers expect an increasing price sequence $p_{1}^{e}<p_{2}^{e}<\cdots<p_{n}^{e}<a$. Then the optimal stopping rule is characterized by a sequence of decreasing cutoff reservation surplus levels $z_{1}>z_{2}>\cdots>z_{n-1}$, where $z_{k} \equiv a-p_{k+1}^{e}$. That is, if a consumer has already sampled $k \leq n-1$ firms, she will search on if the maximum available surplus so far $v_{k} \equiv \max \left\{0, u_{1}-p_{1}, \cdots, u_{k}-p_{k}\right\}$ is less than $z_{k}$; otherwise she will stop searching and buy the best product so far. If a consumer has sampled all products, she will either buy the best one with positive surplus, or leave the market without buying anything.

The optimal stopping rule appears to be "myopic" because at each firm $k \leq n-1$ consumers behave as if there were only one firm left unsampled. We prove it by means of backward induction. When a consumer has already sampled $n-1$ products, according to the definition of $a$ in (1) she should sample the last product if and only if the maximum surplus so far is less than $z_{n}=a-p_{n}^{e}$. Now make the inductive assumption and consider the situation when she has already sampled $k \leq n-2$ products. If $v_{k}$ is less than $z_{k}=a-p_{k+1}^{e}$, then sampling product $k+1$ is always worthwhile. If $v_{k}$ is greater than $z_{k}$, expecting that she will stop searching whatever surplus she discovers at the next firm (because of $v_{k+1} \geq v_{k}>z_{k}>z_{k+1}$ and the inductive assumption), she should actually cease her search now.

This stopping rule also indicates that consumers become more reluctant to keep searching when the search process goes on. This is because they expect increasing prices, not because of fewer options left unsampled. In effect, if consumers expect that all firms are charging the same price $p$, their optimal stopping rule will be stationary with $z=a-p$.

We now derive demand functions. We claim that firm $k$ 's demand when it charges $p_{k}$ is

$$
q_{k}\left(p_{k}\right)=h_{k}\left[1-F\left(z_{k-1}+p_{k}\right)\right]+r_{k}
$$

where

$$
h_{k}=\prod_{j \leq k-1} F\left(z_{k-1}+p_{j}\right)
$$

is the number of consumers who visit firm $k$, and

$$
r_{k}=\sum_{i=k}^{n} \int_{z_{i}}^{z_{i-1}} f\left(u+p_{k}\right) \prod_{j \leq i, \neq k} F\left(u+p_{j}\right) d u .
$$

(For this demand function to be valid for every $k$, we use $z_{0}=a-p_{1}^{e}, z_{n}=0$, and $\prod_{j \leq 0}=1$.)

This demand function can be understood as follows. A consumer will come to firm $k$ if she does not stop at any of the first $k-1$ firms (i.e., if $v_{i}<z_{i}$ for all $i \leq k-$ 
1). This condition is equivalent to $v_{k-1}<z_{k-1}$, because $v_{i}$ increases weakly while $z_{i}$ decreases. Hence, the probability that a consumer visits firm $k$ is $\operatorname{Pr}\left(v_{k-1}<z_{k-1}\right)=h_{k}$. (In particular, $h_{1}=1$ since all consumers sample product 1 first.) This consumer will buy at firm $k$ immediately if she finds that $u_{k}-p_{k} \geq z_{k-1}$. This is because then $v_{k} \geq z_{k-1}>z_{k}$ and so she will stop searching, and at the same time $u_{k}-p_{k} \geq z_{k-1}>v_{k-1}$ and so product $k$ is better than all previous products. The probability of this event is $1-F\left(z_{k-1}+p_{k}\right)$. This explains the first term in (2). It is illustrated as (a) in Figure 1 below.

If a consumer at firm $k$ finds that $u_{k}-p_{k} \in\left[z_{k}, z_{k-1}\right)$, she will not search on either. However, she will now buy product $k$ only if it is better than each previous product. (That is, firm $k$ is now competing with all firms positioned before it but none of those positioned after it.) The (unconditional) probability of this whole event is

$$
\begin{aligned}
& \operatorname{Pr}\left(\max \left\{z_{k}, v_{k-1}\right\} \leq u_{k}-p_{k}<z_{k-1}\right) \\
= & \int_{z_{k}+p_{k}}^{z_{k-1}+p_{k}} \prod_{j \leq k-1} F\left(u_{k}-p_{k}+p_{j}\right) d F\left(u_{k}\right) \\
= & \int_{z_{k}}^{z_{k-1}} f\left(u+p_{k}\right) \prod_{j \leq k-1} F\left(u+p_{j}\right) d u
\end{aligned}
$$

where the second equality is from changing the integral variable from $u_{k}$ to $u=u_{k}-p_{k}$. This explains the first term in $r_{k}$, and we illustrate it as (b) in Figure 1.

If a consumer at firm $k$ finds that $u_{k}-p_{k} \in\left[z_{k+1}, z_{k}\right)$, firm $k$ has demand only if $v_{k-1}$ is also less than $z_{k}$. (Otherwise, product $k$ is dominated at least by some previous product.) Conditional on that, the consumer will continue to sample product $k+1$ but none of further ones. She will come back to buy product $k$ if it is the best one among the first $k+1$ products. (Now firm $k$ is competing not only with all firms positioned before it but also with one firm positioned after it). The (unconditional) probability of this whole event is

$$
\begin{aligned}
& \operatorname{Pr}\left(\max \left\{z_{k+1}, v_{k-1}, u_{k+1}-p_{k+1}\right\}<u_{k}-p_{k}<z_{k}\right) \\
= & \int_{z_{k+1}+p_{k}}^{z_{k}+p_{k}} \prod_{j \leq k+1, \neq k} F\left(u_{k}-p_{k}+p_{j}\right) d F\left(u_{k}\right) \\
= & \int_{z_{k+1}}^{z_{k}} f\left(u+p_{k}\right) \prod_{j \leq k+1, \neq k} F\left(u+p_{j}\right) d u,
\end{aligned}
$$

where the second equality is again from changing the integral variable. This explains the second term in $r_{k}$, and we illustrate it as (c) in Figure 1. Notice that this portion of demand is from consumers who return without sampling all firms. This kind of "midway returning consumers" are absent in the random search model such as Wolinsky (1986) or 
the prominence model with only one prominent firm such as AVZ. In both models, the stopping rule is stationary and consumers will return only if they have sampled all firms. In general, the term indexed by $i$ in $r_{k}$ is firm $k$ 's demand when $u_{k}-p_{k} \in\left[z_{i}, z_{i-1}\right)$.

(a) buy at $k$

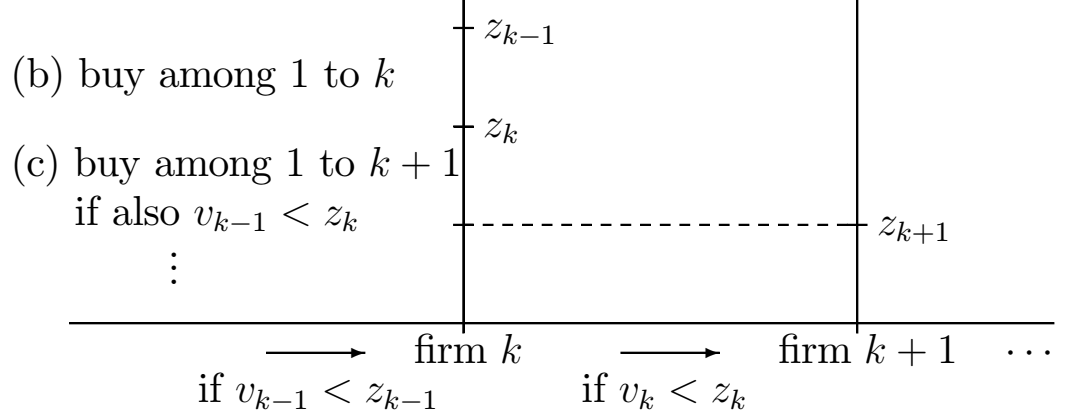

Figure 1: Consumer Decision at Firm $k$

Following the terminology in AVZ (though not precisely), we call the first portion of demand in (2) the "fresh demand" and the second portion of demand (i.e., $r_{k}$ ) the "returning demand". (The first term in $r_{k}$ is from the consumers who stop searching at firm $k$ rather than from returning consumers. In addition, for the last firm, there are no returning consumers literally. We decompose the demand in such a way simply according to the similarity of price sensitivity.) Notice that $h_{k}$ is independent of firm $k$ 's actual price. This is because whether a consumer will visit firm $k$ is only affected her expectation of $p_{k}$. Also notice that a firm's price affects its returning demand only through the density function $f$. In particular, for the uniform distribution, a firm's returning demand is independent of its actual price, and so is less price responsive than fresh demand. When a firm increases its price, more consumes will search on, which implies a larger number of potential returning consumers. (In the first term in $r_{k}$, more consumers will compare it with previous firms.) At the same time, this firm is less likely to win them back in competing with other firms. In the uniform setting, these two effects just cancel out each other.

\subsection{Equilibrium prices and profits}

The above demand analysis is predicated on that consumers hold an expectation of increasing prices. We now show that $p_{1}<p_{2}<\cdots<p_{n}<a$ is indeed an equilibrium. For tractability, from now on we focus on the case with the uniform distribution on [0,1] (i.e., 
$F(u)=u$ ). Then $a$ defined in (1) equals $1-\sqrt{2 s}$. To ensure the existence of equilibrium with $p_{k}<a$ for all $k$ (i.e., every firm is active), we assume that the search cost is relatively small:

$$
s \in(0,1 / 8) \text {, or } a \in(1 / 2,1) .
$$

In the uniform case, as both $h_{k}$ and $r_{k}$ are independent of firm $k$ 's actual price $p_{k}$, profit maximization yields the first-order condition: ${ }^{7}$

$$
h_{k}\left(1-z_{k-1}-2 p_{k}\right)+r_{k}=0
$$

where

$$
h_{k}=\prod_{j \leq k-1}\left(z_{k-1}+p_{j}\right) ; \quad r_{k}=\sum_{i=k}^{n} \int_{z_{i}}^{z_{i-1}} \prod_{j \leq i, \neq k}\left(u+p_{j}\right) d u .
$$

Using the fact that consumers' expectation is fulfilled in equilibrium (i.e., $z_{k-1}=a-p_{k}$ ), we have

$$
p_{k}=1-a+\frac{r_{k}}{h_{k}} .
$$

Since $h_{k}(1-a)$ is firm $k$ 's fresh demand in equilibrium, $r_{k} / h_{k}$ is proportional to the ratio of returning demand to fresh demand. Then (5) implies that a firm whose demand consists of more returning demand proportionally will charge a higher price. This is consistent with the observation that the returning demand is less price sensitive than the fresh demand. It is clear that firm $k$ has more fresh demand than firm $k+1$ (i.e., $h_{k}>h_{k+1}$ ), but it can also be shown that it has more returning demand (i.e., $r_{k}>r_{k+1}$ ). Hence, it is a priori unclear whether $p_{k}<p_{k+1}$ or not.

Although it is infeasible to solve the system of the first-order conditions analytically, we can show that it does have a solution with a sequence of increasing prices. ${ }^{8}$ (All omitted proofs are included in the Appendix.)

Proposition 1 In the uniform-distribution case with condition (3), our ordered search model has an equilibrium with

$$
1-a<p_{1}<p_{2}<\cdots<p_{n}<1 / 2 .
$$

\footnotetext{
${ }^{7}$ In the uniform-distribution setting, the first-order condition is sufficient for no local profitable deviations. However, if firm $k$ deviates to a too high price $\left(p_{k}>1-z_{k-1}\right)$, its fresh demand will become zero and its returning demand will become price dependent. This may make the profit function no longer globally concave. However, as in AVZ, we can show that the profit function is still quasi-concave, and so the first-order condition is also sufficient for no global deviations.

${ }^{8}$ We have not developed a proof for uniqueness, but numerical simulations suggest that, under condition (3), within the region of $[0,1]^{n}$ the system of first-order conditions (5) has a unique solution in $(1-a, 1 / 2)^{n}$.
} 
This result implies that in equilibrium firm $k$ has more fresh demand proportionally than firm $k+1$, and so its demand is more price sensitive. We can also understand this result from the following perspective: the last firm knows that the consumers who went through all the sampling up to this point arrive only because they did not find well-matched products before, and it also knows that these consumers do not face any unsampled options. So it has significant monopoly power over them. Earlier firms on the other hand have an incentive to reduce the price because they want to prevent the consumers from further sampling. The graph below depicts how equilibrium prices vary with the parameter $a$ when there are three firms, where the three curves from the bottom up represent $p_{1}, p_{2}$ and $p_{3}$, respectively. ${ }^{9}$

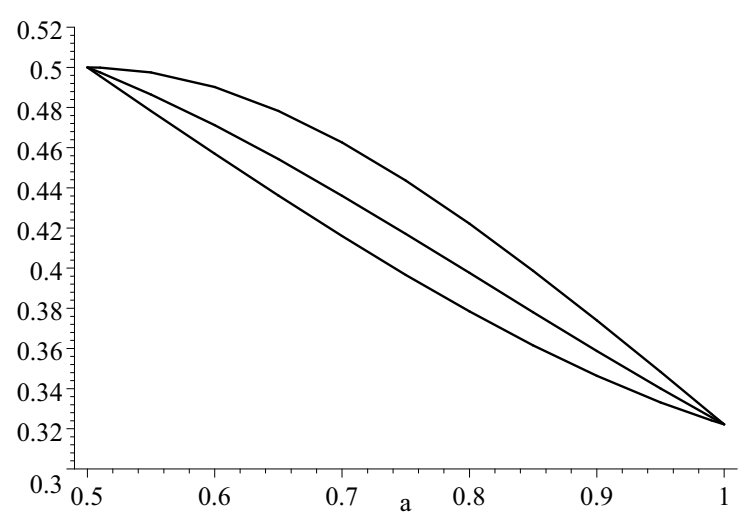

Figure 2: Equilibrium Prices and $a(n=3)$

Several polar cases deserve mention: (i) When the search cost tends to zero (i.e., when $a$ tends to one), consumers sample all firms before they purchase, and so all prices will converge to the full-information equilibrium price $\bar{p}$, say, which satisfies $n \bar{p}=1-\bar{p}^{n}$. (This formula is obtained from (5) by letting $a=1$.) (ii) When the search cost is sufficiently high such that $a \approx 1 / 2$, all prices will converge to the monopoly price $1 / 2$. This is because consumers now stop searching whenever they find a product with positive surplus, and so each firm acts as a monopolist. (iii) When there are a large number of firms in the market (i.e., when $n \rightarrow \infty$ ), all prices will converge to $1-a .^{10}$ This is because with infinitely many firms, from each firm onward the problem looks the same (except that the mass of consumers is shrinking, but that does not matter since how many consumers

\footnotetext{
${ }^{9}$ We expect our price result to hold even for more general distributions so long as the fresh demand is more price sensitive than the returning demand. From the expression for $r_{k}$ in (2), we can see that this is true at least when the density function increases or does not decrease too fast.

${ }^{10}$ We only need to show $p_{n}=1-a+\frac{r_{n}}{h_{n}}$ tends to $1-a$ as $n \rightarrow \infty$. This is true because $\frac{r_{n}}{h_{n}}<$ $\int_{p_{n}}^{a}\left(\frac{u}{a}\right)^{n-1} d u$, and the latter tends to zero as $n \rightarrow \infty$.
} 
will visit a firm is independent of its actual price). Thus, all firms offer the same price and consumers never exercise their recall option. These polar cases suggest that the price dispersion caused by non-random consumer search is most pronounced when the search cost is at an intermediate level and the number of firms is not too large.

In equilibrium, firm $k$ has a larger demand than firm $k+1$ (since both $h_{k}>h_{k+1}$ and $r_{k}>r_{k+1}$ hold), but it charges a lower price. Hence, it is a priori unclear whether firm $k$ earns more or less than firm $k+1$. Let $\pi_{k}$ be firm $k$ 's equilibrium profit. The following result indicates that the demand effect dominates.

Proposition 2 In the equilibrium with a sequence of rising prices, firm 1 earns more than firm 2, and for $k \geq 2$, firm $k$ earns more than firm $k+1$ at least when $a<n /(n+1)$.

Though we only derive a sufficient condition for $\pi_{k}>\pi_{k+1}$ with $k \geq 2$, numerical simulations suggest that it is true for any $a \in(1 / 2,1)$. The following graph depicts how profits vary with the parameter $a$ when there are three firms, where the curves from the top down represent $\pi_{1}, \pi_{2}$ and $\pi_{3}$, respectively.

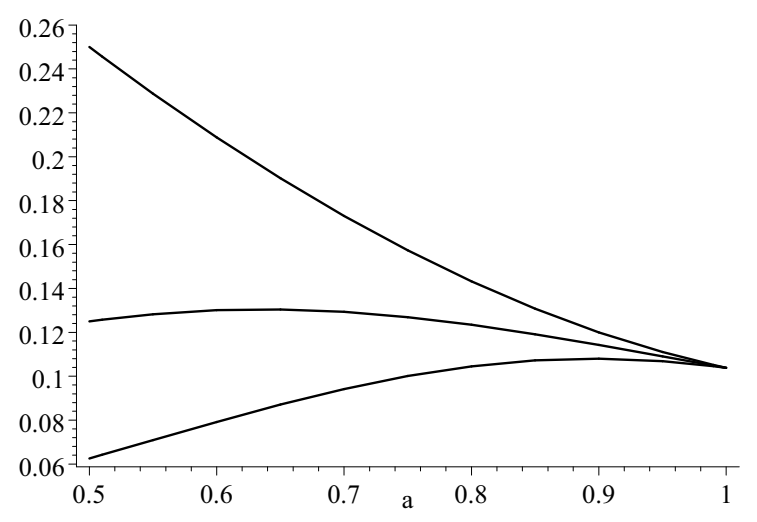

Figure 3: Equilibrium Profits and $a(n=3)$

This example also shows that in an ordered search market firms positioned relatively down in consumer search process can benefit from the reduction of search cost. When the search cost becomes smaller (i.e., when $a$ increases), the market share redistribution effect due to the restricted search order is weakened, which harms top firms but benefits firms in unfavorable positions. At the same time, a smaller search cost implies more intense price competition, which harms all firms. The combination of these two effects explains why $\pi_{1}$ decreases while $\pi_{2}$ and $\pi_{3}$ vary non-monotonically with $a$. 


\subsection{Are there other equilibria?}

Consumers' optimal stopping rule depends on their expectation of the price sequence in the market, and it in turn affects firms' pricing decisions. In equilibrium, the consumer belief should be consistent with the actual prices. Our analysis so far has shown that an equilibrium with a rising price sequence exists. Nevertheless, we have not yet discussed other possible equilibria. We first consider the possibility of an equilibrium with a declining price sequence (as in Arbatskaya, 2007). We still focus on the uniform-distribution setting.

Suppose there is an equilibrium in which consumers hold an expectation of $p_{1}^{e} \geq p_{2}^{e} \geq$ $\cdots \geq p_{n}^{e}$ (but their search order is still restricted) and every firm is active. According to Kohn and Shavell (1974), consumers' optimal stopping rule is well defined and characterized by a sequence of cutoff reservation surplus levels $\left(z_{1}, \cdots, z_{n-1}\right)$. That is, a consumer at firm $k \leq n-1$ will continue to search if and only if the maximum surplus so far is less than $z_{k}$. We can show that $z_{1} \leq \cdots \leq z_{n-1}=a-p_{n}^{e}$ with $z_{k} \geq a-p_{k+1}^{e}$ for all $k \leq n-2 .{ }^{11}$ So consumers will become more willing to search on as the search process goes on. This is qualitatively different from the stopping rule when consumers expect a rising price sequence. (To have a unified expression for demand functions, we use $z_{n}=a-p_{n}^{e}$.)

Now we derive demand functions. A consumer will visit firm $k$ if and only if $u_{i}-p_{i}<z_{i}$ for all $i \leq k-1$. If she finds out $u_{k}-p_{k} \geq z_{k}$, she will stop searching and buy product $k$ since it is better than all previous products (due to the increasing $z_{i}$ ). If she finds out $u_{k}-p_{k}<z_{k}$, she will continue to search, and will eventually return to buy at firm $k$ if she has sampled all products (again due to the increasing $z_{i}$ ) and product $k$ has the highest positive surplus. Hence, firm $k$ 's demand is

$$
\begin{aligned}
q_{k}\left(p_{k}\right)= & \operatorname{Pr}\left(u_{i}-p_{i}<z_{i} \text { for } i \leq k-1 \text { and } u_{k}-p_{k} \geq z_{k}\right) \\
& +\operatorname{Pr}\left(u_{i}-p_{i}<z_{i} \text { for } i \leq k-1 \text { and } \max \left\{v_{k-1}, u_{j}-p_{j}\right\}_{j \geq k+1}<u_{k}-p_{k}<z_{k}\right) \\
= & h_{k}\left[1-\left(p_{k}+z_{k}\right)\right]+r_{k},
\end{aligned}
$$

where $h_{k}=\prod_{i \leq k-1}\left(z_{i}+p_{i}\right)$ is the number of consumers who visit firm $k$, and $r_{k}$ represents the number of returning consumers. (Notice that, due to the increasing cutoff reservation

\footnotetext{
${ }^{11}$ Keep the notation $v_{k} \equiv \max \left\{0, u_{1}-p_{1}, \cdots, u_{k}-p_{k}\right\}$. First of all, at firm $n-1, z_{n-1}=a-p_{n}^{e}$ is simply from the definition of $a$. Now consider a consumer at firm $n-2$. If $v_{n-2}<a-p_{n-1}^{e}$, then sampling product $n-1$ is always worthwhile. If $v_{n-2} \geq z_{n-1}$, this consumer will never sample firm $n$ no matter what surplus she discovers at firm $n-1$, and so she has no incentive to just visit firm $n-1$ since $v_{n-2} \geq z_{n-1}=a-p_{n}^{e} \geq a-p_{n-1}^{e}$. Thus, the cutoff reservation surplus level at firm $n-2, z_{n-1}$, must be between $a-p_{n-1}^{e}$ and $z_{n-1}$. The same logic can go backward further to explain the stopping rule.
} 
surplus levels, there are now no midway returning consumers any more.) Two observations are useful: (i) in our uniform setting, $r_{k}$ is again independent of firm $k$ 's actual price $p_{k}$; (ii) $r_{k} \leq r_{k+1}$. The latter is because, if a consumer has left both firm $k$ and firm $k+1$, the former's product must on average have a lower net surplus given $z_{k} \leq z_{k+1}$, and so it can win this consumer back less likely.

Due to the restricted search order, firm $k$ tends to have more fresh demand than firm $k+1$. At the same time, firm $k$ has less returning demand than firm $k+1$. Since the fresh demand is again more price sensitive than the returning demand, firm $k$ will have an incentive to charge a lower price. This leads to a contradiction. We formalize this argument in the Appendix.

Proposition 3 In the uniform-distribution case, our ordered search model has no equilibrium in which all firms are active and they charge declining prices $p_{1} \geq p_{2} \geq \cdots \geq p_{n}$.

Since $p_{1}$ does not affect consumers' stopping rule once they participate in the market, our analysis also implies that, when $n \geq 3$, there is no equilibrium with $p_{1}<p_{2} \geq \cdots \geq$ $p_{n} .{ }^{12}$ However, it is difficult to further rule out the possibility of other equilibria with non-monotonic price sequences. This is mainly because for different non-monotonic price sequences, consumers' optimal stopping rule usually has different properties. So it is hard to discuss all hypothetical non-monotonic equilibria in a unified way. However, in the three-firm case, we can show that there is no non-monotonic equilibrium. In that case, the only remaining case we need to deal with is $p_{1} \geq p_{2}<p_{3}$. Since $p_{1}$ does not affect the stopping rule, our analysis for a rising price sequence applies. The discussion in footnote 8 suggests that, under the condition $s \in(0,1 / 8), p_{1} \geq p_{2}$ cannot take place together with $p_{2}<p_{3}$.

\section{Conclusion}

This paper has presented an ordered search model with differentiated products in which consumers search both for price and product fitness. We have constructed an equilibrium in which there is price dispersion and prices rise in the order of search. The top firms in consumer search process, though charge lower prices, earn higher profits due to their larger market shares. We also ruled out the possibility of equilibrium with a declining price sequence.

\footnotetext{
${ }^{12}$ If $n=2$, one can see that our proof of Proposition 3 does not work for $p_{1}<p_{2}$.
} 
Our analysis is restricted to the case where all consumers have the same search cost. If consumers have heterogenous search costs (as in Arbatskaya, 2007), those with higher search costs are more likely to buy at the top firms, which provides the top firms an incentive to charge higher prices. If there is no product differentiation, as Arbatskaya (2007) has shown, prices should then decline with the rank of firms. With product differentiation, however, this effect should be balanced with the opposite one identified in this paper. The final prediction will depend on the relative importance of the two effects.

We have also restricted our attention to the case with an exogenous search order. However, our equilibrium still survives even if we allow consumers to choose their search orders freely. This is because in our model products in top positions are cheaper than others and so it is rational to sample them first. ${ }^{13}$ Alternatively, we could also endogenize consumer search order through, for example, advertising competition or bidding for online paid placements. Hann and Moraga-Gonzalez (2009) consider a similar search model with differentiated products in which a consumer's likelihood of sampling a firm is proportional to that firm's advertising intensity. But in symmetric equilibrium, all firms set the same price and advertise with the same intensity, and consumers end up searching randomly. They also constructed a non-random search equilibrium in the duopoly case by introducing asymmetric advertising technologies among firms. Chen and He (2006), and Athey and Ellison (2008) present two auction models in which advertisers bid for sponsor-link positions on a search engine. Distinct from other papers on position auctions, they have a formal search model in the consumer side. In equilibrium, consumers search through the sponsor links in the order presented since they anticipate that high-quality links will be placed higher up the listing, and higher-quality firms do have a greater incentive to buy top positions given consumers' search order. But there is no effective price competition in both papers, and so no role for non-random consumer search to affect market prices. ${ }^{14}$

\section{A Appendix}

\section{A.1 Proof of Proposition 1}

We will first show that, in the uniform setting, under the condition $a \in(1 / 2,1)$ our ordered search model has an equilibrium with $1-a \leq p_{1} \leq \cdots \leq p_{n} \leq 1 / 2$. We will then

\footnotetext{
${ }^{13}$ With a free choice of search order, random search with a uniform price across firms will also become an equilibrium outcome.

${ }^{14}$ Chen and He (2006) do have prices charged by advertisers, but the structure of consumer demand in their model means that the Diamond Paradox is present, and all firms set monopoly prices.
} 
exclude the possibility of equalities.

Suppose consumers hold an expectation of $\mathbf{p}^{e}=\left(p_{1}^{e}, \cdots, p_{n}^{e}\right)$ with $1-a \leq p_{1}^{e} \leq \cdots \leq$ $p_{n}^{e} \leq 1 / 2$. Given other firms' prices $p_{-k}$, the demand function of firm $k$ is

$$
q_{k}\left(p_{k}\right)=h_{k}\left(1-z_{k-1}-p_{k}\right)+r_{k},
$$

where

$$
h_{k}=\prod_{j \leq k-1}\left(z_{k-1}+p_{j}\right) ; \quad r_{k}=\sum_{i=k}^{n} \int_{z_{i}}^{z_{i-1}} \prod_{j \leq i, \neq k}\left(u+p_{j}\right) d u .
$$

More precisely, since we are using uniform distribution on $[0,1]$, every term $\left(x+p_{j}\right)$ in $h_{k}$ and $r_{k}$ should be replaced by $\min \left\{1, x+p_{j}\right\}$. Notice that both $h_{k}$ and $r_{k}$ are independent of firm $k$ 's actual price $p_{k}$, and so we can write the first-order condition as ${ }^{15}$

$$
2 p_{k}=1-z_{k-1}+\frac{r_{k}}{h_{k}}
$$

Step 1: Given $p^{e}$, the system of (6) for $k=1, \cdots, n$ has a solution with

$$
p_{k}=\gamma_{k}\left(\mathbf{p}^{e}\right) \in[1-a, 1 / 2], k=1, \cdots, n .
$$

Equation (6) defines the best response of $p_{k}$ to other prices $p_{-k}$, which we denote $p_{k}=b_{k}\left(p_{-k} ; \mathbf{p}^{e}\right)$. First, from $2 p_{k} \geq 1-z_{k-1}=1-a+p_{k}^{e} \geq 2(1-a)$, we have $p_{k} \geq 1-a$. Second, since $z_{i}$ decreases and $z_{n}=0$, we have

$$
r_{k} \leq h_{k} \sum_{i=k}^{n}\left(z_{i-1}-z_{i}\right)=h_{k} z_{k-1},
$$

and so (6) implies $p_{k} \leq 1 / 2$. Hence, given $\mathbf{p}^{e}$ we have a continuous mapping

$$
\mathbf{b}\left(\mathbf{p} ; \mathbf{p}^{e}\right)=\left[b_{1}\left(p_{-1} ; \mathbf{p}^{e}\right), \cdots, b_{n}\left(p_{-n} ; \mathbf{p}^{e}\right)\right]
$$

from $[1-a, 1 / 2]^{n}$ to itself. The Brouwer fixed-point theorem yields our result. The implicit function theorem also implies that $\gamma_{k}\left(\mathbf{p}^{e}\right)$ are continuous functions.

Step 2: Given $p^{e}$, we have $\gamma_{k+1}\left(\mathbf{p}^{e}\right) \geq \gamma_{k}\left(\mathbf{p}^{e}\right)$.

From (6), we have

$$
2\left(p_{k+1}-p_{k}\right)=z_{k-1}-z_{k}+\frac{r_{k+1}}{h_{k+1}}-\frac{r_{k}}{h_{k}} \geq z_{k-1}-z_{k}+\frac{1}{h_{k}}\left(r_{k+1}-r_{k}\right),
$$

\footnotetext{
${ }^{15}$ Some readers may wonder why we do not directly deal with the first-order conditions in (5) (which have used the belief consistency condition). It turns out to be technically more difficult.
} 
where the inequality is because $h_{k} \geq h_{k+1}$. (The equality holds if both of them equal to one.) On the other hand, if we let

$$
A=\sum_{i=k+1}^{n} \int_{z_{i}}^{z_{i-1}} \prod_{j \leq i, \neq k, k+1}\left(u+p_{j}\right) d u
$$

then

$$
\begin{aligned}
r_{k+1}-r_{k} & =\left(p_{k}-p_{k+1}\right) A-\int_{z_{k}}^{z_{k-1}} \prod_{j \leq k-1}\left(u+p_{j}\right) d u \\
& \geq\left(p_{k}-p_{k+1}\right) A-\left(z_{k-1}-z_{k}\right) h_{k} .
\end{aligned}
$$

Therefore,

$$
2\left(p_{k+1}-p_{k}\right) \geq \frac{A}{h_{k}}\left(p_{k}-p_{k+1}\right)
$$

which implies $p_{k+1}-p_{k} \geq 0$.

Step 3: The above analysis implies that, for any consumer expectation $\mathbf{p}^{e}$ in the domain of $\Omega=\left\{\mathbf{p} \in[1-a, 1 / 2]^{n}: p_{1} \leq \cdots \leq p_{n}\right\}$ (which is compact and convex), the price competition has an equilibrium $\gamma\left(\mathbf{p}^{e}\right)=\left[\gamma_{1}\left(\mathbf{p}^{e}\right), \cdots, \gamma_{n}\left(\mathbf{p}^{e}\right)\right]$ which also lies in $\Omega$. Moreover, $\gamma\left(\mathbf{p}^{e}\right)$ in continuous in $\Omega$. Thus, the Brouwer fixed-point theorem implies that our ordered search model has an equilibrium in $\Omega$.

Step 4: We now exclude the equality possibility. First, given $p_{k} \leq 1 / 2$, in equilibrium $z_{k-1}=a-p_{k}>0$ under the condition $a \in(1 / 2,1)$. Also recall that we use $z_{n}=0$. Thus, $r_{k}>0$ and so equation (5) in the main text implies $p_{k}>1-a$. Second, notice that in equilibrium

$$
r_{n}=\int_{0}^{a-p_{n}} \prod_{j \leq n-1}\left(u+p_{j}\right) d u<h_{n}\left(a-p_{n}\right) .
$$

So equation (5) for $k=n$ implies $p_{n}<1 / 2$. Finally, given the equilibrium price $\mathbf{p} \in \Omega$ and the condition $a \in(1 / 2,1), h_{k}$ is strictly greater than $h_{k+1}$. Then, a similar argument as in Step 2 implies $p_{k+1}>p_{k}$.

\section{A.2 Proof of Proposition 2}

Notice that $\pi_{k}>p_{k+1} q_{k}\left(p_{k+1}\right)$ since firm $k$ can at least charge the same price as firm $k+1$. Thus, it suffices to show $q_{k}\left(p_{k+1}\right)>q_{k+1}\left(p_{k+1}\right)$, or

$$
h_{k}\left(1-a+p_{k}-p_{k+1}\right)+r_{k}>h_{k+1}(1-a)+r_{k+1} .
$$

(Due to the higher cutoff reservation surplus level at firm $k$, it may now have less fresh demand than firm $k+1$.) Decompose $r_{k}$ into two parts: $r_{k}=A_{k}+B_{k}$, where

$$
A_{k}=\int_{a-p_{k+1}}^{a-p_{k}} \prod_{j \leq k-1}\left(u+p_{j}\right) d u
$$


is the first term in $r_{k}$ and $B_{k}$ includes all other terms. It is ready to see $B_{k}>r_{k+1}$ since $p_{k}<p_{k+1}$.

For $k=1$, we further have $A_{k}=h_{k}\left(p_{k+1}-p_{k}\right)$, and so (7) holds since $h_{k}>h_{k+1}$. That is, firm 1 must earn more than firm 2.

For $k \geq 2$, we have

$$
A_{k}>\left(p_{k+1}-p_{k}\right) \prod_{j \leq k-1}\left(a-p_{k+1}+p_{j}\right)>\left(p_{k+1}-p_{k}\right) h_{k+1},
$$

and so $(7)$ holds if $\left(h_{k}-h_{k+1}\right)\left[1-a-\left(p_{k+1}-p_{k}\right)\right]>0$, or equivalently $p_{k+1}-p_{k}<1-a$. A looser sufficient condition is $r_{k+1} / h_{k+1}<1-a$ by using (5). Moreover, we know that $r_{k} / h_{k}$ increases with $k$, and so it suffices to show $r_{n} / h_{n}<1-a$. From

$$
\frac{r_{n}}{h_{n}}<\int_{p_{n}}^{a}\left(\frac{u}{a}\right)^{n-1} d u=\frac{a^{n}-p_{n}^{n}}{n a^{n-1}}<\frac{a}{n},
$$

we obtain the sufficient condition $a<n /(n+1)$.

\section{A.3 Proof of Proposition 3}

We continue our argument in Section 3.3. Given the demand functions derived under consumers' expectation of a declining price sequence, profit maximization yields the firstorder conditions:

$$
h_{k}\left(1-z_{k}-2 p_{k}\right)+r_{k}=0
$$

for all $k$. In particular, for firm $n$ we have

$$
h_{n}\left(1-a-p_{n}\right)+r_{n}=0
$$

by using $z_{n}=a-p_{n}$ in equilibrium, and so $1-a-p_{n}<0$. If $p_{1} \geq \cdots \geq p_{n}$, then the first-order condition for any firm $k \leq n-1$ implies

$$
0=h_{k}\left(1-z_{k}-2 p_{k}\right)+r_{k} \leq h_{k}\left(1-a-p_{k}\right)+r_{k}<h_{n}\left(1-a-p_{n}\right)+r_{n}
$$

where the first inequality is because $z_{k} \geq a-p_{k+1} \geq a-p_{k}$, and the second one is because $p_{k} \geq p_{n}, h_{k}>h_{n}$ and $r_{k} \leq r_{n}$. This, however, contradicts to (9).

\section{References}

Anderson, S., and R. Renault (1999): "Pricing, Product Diversity, and Search Costs: A Bertrand-Chamberlin-Diamond Model," RAND Journal of Economics, 30(4), 719735 . 
Arbatskaya, M. (2007): "Ordered Search," RAND Journal of Economics, 38(1), 119126.

Armstrong, M., J. Vickers, and J. Zhou (2009): "Prominence and Consumer Search," Rand Journal of Economics, 40(2), 209-233.

Athey, S., and G. Ellison (2008): "Position Auctions with Consumer Search," mimeo.

Chen, Y., And C. He (2006): "Paid Placement: Advertising and Search on the Internet," mimeo.

Hann, M., and J. Moraga-Gonzalez (2009): "Advertising for Attention in a Consumer Search Model," mimeo.

Hortaçsu, A., and C. Syverson (2004): "Product Differentiation, Search Costs, and Competition in the Mutual Fund Industry: A Case Study of S\&P 500 Index Funds," Quarterly Journal of Economics, 119(2), 403-456.

Kohn, M., and S. Shavell (1974): "The Theory of Search," Journal of Economic Theory, 9(2), 93-123.

Perry, M., And A. Wigderson (1986): "Search in a Known Pattern," Journal of Political Economy, 94(1), 225-230.

Wolinsky, A. (1986): "True Monopolistic Competition as a Result of Imperfect Information," Quarterly Journal of Economics, 101(3), 493-511. 